\section{Does business strategy and management control system fit determine performance?}

Do strategy and MCS determine performance

Tapio Jukka School of Business and Economics, University of Jyväskylä, Jyväskylä, Finland
Abstract

Purpose - This study examines the relationship between business strategy, management control system (MCS) type and performance. Does the alignment of organisation business strategy and MCS fresult in better performance?

Design/methodology/approach - This study draws on the business strategy and MCS type literature to identify business strategies and MCS types. A scoring method was used to identify business strategy types and cluster analysis to identify MCS types from a sample of 80 firms and 621 firm-years of data. Analysis of variance was used analyse the differences.

Findings - Four types of MCS were identified and were labelled clan, adhocracy, market and hierarchy. The sample was split into defender, analyser, prospector and reactor strategies. The results showed defender strategies performed better with hierarchy or market type MCSs while prospector strategies performed better with clan or adhocracy MCS types. Analysers performed acceptably with all MCS types.

Practical implications - The results of this study suggest that organisations should align their business strategy with a certain MCS type to achieve good performance. Also, alignment of top management and business strategy is supported as the top management properties differ between the MCS types.

Originality/value - This research contributes to the management control and strategy literature by demonstrating how the alignment between organisation business strategy and organisation-level MCS type determines organisational performance. The results suggest that differing business strategies yield better performance when aligned with the appropriate management controls represented by an MCS type.

Keywords Management control system, Business strategy, Performance, Typology

Paper type Research paper

\section{Introduction}

While the relationship between business strategy and the use and design of management controls to implement it has received considerable attention, our knowledge on this relationship and its effects is still fragmented (Chenhall, 2003; Otley, 2016). Management controls are the processes and mechanisms managers use to influence the behaviour of individuals and groups towards the predetermined objectives and goals of the organisation. These controls can include personal supervision, performance measurement or reward systems, and these control processes and mechanisms are merged and used together as management control systems (MCSs). Depending on how control in an organisation is imposed by management, differing MCS types can be identified. The objectives and goals are derived from the organisation's long-term plans and strategies on how it will compete in its industry and adapt to its environment. However, successful implementation of differing strategies

(C) Tapio Jukka. Published by Emerald Publishing Limited. This article is published under the Creative Commons Attribution (CC BY 4.0) licence. Anyone may reproduce, distribute, translate and create derivative works of this article (for both commercial and non-commercial purposes), subject to full attribution to the original publication and authors. The full terms of this licence may be seen at http:// creativecommons.org/licences/by/4.0/legalcode

Funding: This research was supported by University of Jyväskylä grants 1/13.00.04.00/2015 and 2018 awarded to Tapio Jukka. 
IJPPM

72,3

660 requires different types of management controls and the fit between the strategy and MCS type may determine the organisation's performance (Chenhall, 2003; Kihn, 2010).

There are several definitions for strategy. Often, strategy is defined as a unified, comprehensive and integrated plan of action and patterns in a stream of actions and decisions that guide the organisation toward predefined goals and objectives (Mintzberg, 1996a). Strategic decisions take place on many levels in the organisation and concern different aspects of the organisations tasks. Corporate strategy considers the choices of what businesses to operate in, acquisition and divestment of businesses and how to finance and structure the organisation (Langfield-Smith, 1997). Business or competitive strategies deal with the organisation's business units and how these compete and position themselves in their respective markets (Langfield-Smith, 1997). Finally, operational strategies define how the different functions of the organisation contribute to the organisation's business strategy.

Management control systems are the collection of control processes and mechanisms management uses to reach their organisations predetermined objectives and goals (Malmi and Brown, 2008). Management selects the appropriate combination of these controls to fit their firm's contextual conditions. These control processes and mechanisms are not used separately; instead, they are combined and used together as management control systems (Malmi and Brown, 2008). There is substantial literature proposing various frameworks for MCSs (e.g. Bedford and Malmi, 2015; Ferreira and Otley, 2009; Malmi and Brown, 2008; Simons, 1995). These frameworks are aimed at the study of the individual parts and characteristics of a single MCS (Strauß and Zecher, 2013). Another stream of MCS literature seeks to identify MCS archetypes (e.g. Lebas and Weigenstein, 1986; Ouchi, 1979; Speklé, 2001; Whitley, 1999). These typologies allow to address control in its entirety on an organisational level instead of the level of individual controls and processes (Speklé, 2001).

There has been considerable interest in the relationship between business strategy, MCS and performance, and the literature can be classified into three streams. The first stream examines the effect of strategy on MCS and sees the MCS basically as a strategy implementation tool (Gani and Jermias, 2012). The MCS should be designed to support the business strategy to gain competitive advantage and superior performance (Langfield-Smith, 1997). The second stream of literature looks at the effect of the MCS on strategy and considers MCSs as systems management use to craft strategies (Gani and Jermias, 2012). The MCS plays a substantial role in the business strategy formulation and has continuous implication throughout the strategic management process (Henri, 2006a). The third stream of literature takes a contingency theory approach and asserts that some MCSs are more suited to certain business strategies than others, or in other words the organisations business strategy and MCS should be aligned (Chenhall, 2003; Gani and Jermias, 2012). Thus, strategy and MCS interact in a system where MCS facilitates crafting a business strategy and the MCS processes and mechanisms change to match the business strategy (Gani and Jermias, 2012; Kober et al., 2007).

Although the relationship between business strategy, MCS and performance has received interest in the management accounting and strategy literature, the results are still ambiguous (Chenhall, 2003; Langfield-Smith, 1997; Otley, 2016). These unclear results can be attributed to differing conceptualisations and operationalisations of business strategy and MCS. Although the limited number of generic business strategy typologies applied in the extant studies share similarities, comparing strategy constructs between them might prove problematic (Tucker et al., 2009). Also, as Langfield-Smith (1997) notes that often no difference between intended and realised strategies were made and the presence of certain management controls did not mean they were used. Otley (2016) suggests that the fragmented results are partly due to the varied dimensions of the control systems used in the studies. Tucker et al. (2009) found MCSs were operationalised using specific features of a MCS picked from an inventory of possible controls. Although there are many studies linking individual management controls with performance, the results are still equivocal and fragmented. A more consistent and coherent 
view of the relationship between business strategy, MCS and performance can be achieved using archetypes to operationalise business strategy and MCS. Business strategies reveal how organisations as a whole adapt to changes in their environment (Miles and Snow, 1978). Similarly, an MCS archetype is a characteristic configuration of control structures and practices that allow to address control in its entirety at the organisational level instead at the level of individual controls and structures (Speklé, 2001).

To further our understanding of the relationship between business strategy, MCS and performance, this study examines the association of organisation-level business strategy and MCS type with performance. Using the Miles and Snow (1978) business strategy typology and an organisation-level MCS typology (Jukka and Pellinen, 2020; Ouchi, 1979; Speklé, 2001; Whitley, 1999) this study addresses the following research question: Does the alignment of organisation business strategy and MCS result in better performance? Or in other words, does a certain business strategy work better with a certain type MCS? This research contributes to the management control and strategy literature by demonstrating that the organisation-level MCS type should be aligned with the organisation's business strategy to enhance performance. A defender business strategy performs better with a hierarchy or market type MCS while a prospector business strategy performs better with a clan- or adhocracy-type MCS. The results also suggest that the MCS types reflect how management seeks to solve the administrative problem of the adaptive cycle and that certain MCS types are better suited than others to solve the entrepreneurial or the engineering problems. As a third contribution, this study demonstrates the use of archival accounting and TMT data as proxies for organisationlevel MCS archetypes and business strategies to study the MCS - business strategy link.

The paper proceeds as follows. First, the relevant literature on business strategy and MCS types are reviewed and hypotheses drawn. Then the data and methods are described followed by the results. Finally, the theoretical and managerial implications of the study are discussed.

\section{Literature review}

\subsection{Business strategy}

Business strategies explain how firms compete in their respective market environments and seek to achieve superior performance. Management literature has proposed several business strategy typologies. Miles and Snow (1978) categorise business strategies as defender, analyser, prospector or reactor while Porter (1980) categorises them in terms of differentiation, cost leadership, focus or stuck in the middle. March (1991) separates business strategies based on exploration and exploitation. Treacy and Wiersema (1995) suggest business strategies based on operational excellence, customer intimacy or product leadership. Although the names of the strategies differ between the typologies, they share common attributes. The defender strategy of Miles and Snow (1978) is similar to Porter's (1980) cost leadership, March's (1991) exploitation and Treacy and Wiersema's (1995) operational excellence while the prospector strategy of Miles and Snow (1978) aligns with Porter's (1980) differentiation, March's (1991) exploration and Treacy and Wiersema's (1995) product leadership (Bentley et al., 2013).

Miles and Snow (1978) propose four business strategies. The three viable strategies form a strategy continuum with defenders and prospectors at the opposing ends and analysers between these two. The fourth strategy, reactors, is an unstable failed strategy. There are two reasons for choosing this business strategy typology. First, the business strategy continuum enables the operationalisation of strategy as a continuous measure derived from archival data while the other typologies require personal interviews and surveys of informants (Bentley et al., 2013; Ittner et al., 1997). Second, while the other typologies define strategies as discrete alternatives (March, 1991; Porter, 1980; Treacy and Wiersema, 1995), there are similarities between the business strategies of the different typologies allowing the generalisation of the results to the business strategies of alternative theories.

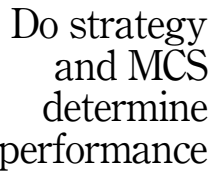

661 
IJPPM

72,3

662

Miles and Snow (1978) define defenders as firms with narrow product-market domains and focused on efficiency. The narrow and stable markets are aggressively maintained with competitive pricing and excellent customer service. Developments outside the domain are largely ignored and research and development focus on improving existing goods and services. Growth is modest but steady through market penetration. Technological efficiency is central to defenders resulting in heavy investment and continuous improvements in the core technology. Financial and production expertise prevail in the top management of these firms and their tenures are long with promotions from within. Organisational structures reflect centralised control with functional structure and division of labour.

Prospectors are firms that continuously search for market opportunities (Miles and Snow, 1978). These firms attend to a broad and developing domain and continuously monitor the environmental conditions and events. Growth is fast and can happen in spurts induced by product and market development. These firms avoid long-term commitment to a single technology by applying multiple flexible technologies and investing in people. Top management is numerous consisting often of marketing and R\&D expertise. Their tenures are short, and managers may be hired from outside. Control is decentralised and organisations display product structures and low division of labour.

Miles and Snow (1978) define analysers as firms that operate in two product-market domains and try to balance these two often-conflicting domains. Analysers combine defender and prospector characteristics to form their unique strengths and weaknesses. Analysers seek new market and product opportunities while maintaining a solid base of their traditional goods and services. Stable growth is accomplished with market penetration and productmarket development. These firms exhibit both stable, efficient technology and flexible technologies. The top management consists of marketing, applied research and production expertise. Control is moderately centralised with complex matrix organisational structures.

In addition to the three viable strategies, Miles and Snow (1978) also introduce an unsuccessful strategy, the reactor. It is an unstable and inconsistent organisation that fails to adapt to the changing environment. This is often a result of management's failure to present a viable business strategy, the organisation's technology, structure and process are not suited to the organisation strategy, or management maintains to a strategy-structure relationship which is no longer relevant. Due to their ambiguous nature and inconsistent behaviour, reactors are often omitted from studies and only the viable strategies are considered (Blackmore and Nesbitt, 2013). Omission to identify the reactors and categorise them within the viable firms can distort the strategy-performance link as reactors are considered unviable or unprofitable (Hambrick, 1983; Miles and Snow, 1978).

\subsection{MCS typologies}

The extant management and accounting literature have generated several MCS typologies. In their review, Strauß and Zecher (2013) identified four typologies suited to typing and differentiating whole organisation-level MCSs. Ouchi (1979) uses a transaction cost economics (TCE) approach to classify organisational evaluation and control systems into market, bureaucracy and clan mechanisms. Similarly, using the TCE approach Lebas and Weigenstein (1986) also identify the three types of MCSs, but use different names: market, rules and culture approaches (Strauß and Zecher, 2013). In the market types, external market mechanisms are used to control behaviour. Externally set rules and output controls are used in the bureaucracy and rules types, while rituals, internalised beliefs and values are used to influence behaviour in the clan and culture types.

Whitley (1999) suggests a typology of four different control systems based on the comparative sociology approach. His output-based control systems align with the market types of the earlier typologies (Lebas and Weigenstein, 1986; Ouchi, 1979). Whitley's bureaucratic 
control systems are similar to bureaucracy and rules, while patriarchal control systems resemble clan and culture types in Ouchi's (1979) or Lebas and Weigenstein's (1986) typologies. The fourth control system in Whitley's MCS typology is delegated control systems, where autonomous groups or units in the organisation apply control.

Spekle (2001) returns to the TCE approach and introduces a five control type MCS typology. Four of his control types correspond to the types in the earlier typologies. Speklés (2001) market and machine controls align with the market and bureaucracy types while his boundary control based on interdicts and limitations aligns with clan, culture and patriarchal controls in the earlier typologies. His exploratory control relies on information sharing and the emergence of insights to achieve control and is similar to Whitley's (1999) delegated control systems. Speklé (2001) introduces arm's length control, which incorporates elements of the competitive market and administrative machine controls and does not have an equivalent in the earlier typologies.

Viewing organisations from an effectiveness perspective, Quinn and Rohrbaugh (1983) used organisational effectiveness measures applied in organisation analysis to differentiate organisation types. Their competing values framework (CVF) consists of three value dimensions (control-flexibility, internal-external and means-ends) that explain conceptualisations of organisational effectiveness. The two main dimensions form four quadrants differentiating organisational structure with values of control and stability to flexibility and individuality and organisational focus from an internal view on the people in the organisation to an external view on the organisation itself. The four quadrants represent differing organisation types identified as clan, adhocracy, market and hierarchy, and each type has distinctive organisational effectiveness criteria or measures. The CVF enables the identification of distinct organisational effectiveness and performance measures for each quadrant or organisation type that reflect the associated values and applied management controls of that organisation type (Cooper and Quinn, 1993).

The four organisation models in the CVF are comparable with the reviewed MCS types (Jukka and Pellinen, 2020). The clan, market and hierarchy types in the CVF have directly matching MCS types (Büschgens et al., 2013; Yu and Wu, 2009). The human relations approach of the clan type coincides with the clan, culture, patriarchal and boundary MCS types. Correspondingly, the rational goal-oriented approach of the market type matches the market and output-based MCS types and the hierarchy corresponds with the bureaucracy, rules and machine types. The open systems adhocracy type matches the delegated and exploratory control types of Whitley (1999) and Speklé (2001) with emerging insights and autonomy central in accomplishing control.

Quinn and Rohrbaugh (1983) use the applied organisational effectiveness measures to differentiate the organisation types. Thus, each CVF and MCS type has distinctive performance criteria or measures associated with it and these can be utilised to differentiate them. The subsequent CVF literature has identified an array of organisation properties and effectiveness measures characteristic for each organisation type (e.g. Cooper and Quinn, 1993; Hartnell et al., 2011; O'Neill and Quinn, 1993; Zammuto and O'Connor, 1992). Given that each organisation type has characteristic and identifiable effectiveness criteria and measures, the organisation and MCS types can be identified from these effectiveness criteria and measures. Jukka and Pellinen (2020) suggested top management team (TMT) size, firm size, TMT output functional background, TMT throughput functional background, TMT peripheral functional background, TMT general management background, TMT age, firm tenure and team tenure as measures that can be used to group firms with similar organisation-level MCS types.

Although increasing TMT size has been shown to improve firm performance, it has also been linked with increasing communication and coordination problems (Certo et al., 2006; Haleblian and Finkelstein, 1993). Thus, adhocracy control pursuing agility should exhibit small TMTs able to make quick decisions, while hierarchy control underscoring stability
Do strategy and MCS determine performance

663 
IJPPM 72,3

\section{4}

would exhibit large TMTs (Cameron and Lavine, 2006; Quinn and Rohrbaugh, 1983). Similarly, firm size separates adhocracy and hierarchy control as small firms are more adaptive and ready to change than larger more bureaucratic firms (Abebe, 2010; Baliga and Jaeger, 1984).

The upper echelons theory (Hambrick and Mason, 1984) asserts the decisions and actions of TMTs are linked with their functional backgrounds classified as output, throughput and peripheral functional backgrounds. Output functions include marketing, sales and R\&D emphasising growth and search for new opportunities and markets (Abebe, 2010; Hambrick and Mason, 1984). Thus, adhocracy and market control should have higher share of output functional backgrounds as the CVF suggests adhocracies value growth and market organisations value search for new opportunities and markets (Hartnell et al., 2011; Zammuto and O'Connor, 1992). Production, process engineering and accounting are considered throughput functional backgrounds and they strive to improve the transformation process (Abebe, 2010; Hambrick and Mason, 1984). The CVF suggests that clan control applies to process-oriented leadership, while adhocracy control applies to improvement-oriented leadership (O’Neill and Quinn, 1993; Wang et al., 2015), making throughput functional backgrounds more common with these control types.

TMT members who are not directly involved with the organisation's core activities (e.g. law, finance, personnel and administrative backgrounds) are considered as peripheral functional backgrounds (Hambrick and Mason, 1984). A higher share of peripheral backgrounds would benefit clan control, where teamwork, participation and human resource development are valued (Hartnell et al., 2011). Also, peripheral functional backgrounds are valuable in formal planning, coordination and maintaining structures important to hierarchy and goal-oriented market control (Hambrick and Mason, 1984; O’Neill and Quinn, 1993).

Not all top executives hold a functional background (Jukka and Pellinen, 2020; Koch et al., 2017). Instead, they have general management backgrounds and possess generic governance expertise from long tenures in large firms (Biemann and Wolf, 2009; Koch et al., 2017). Thus, general management backgrounds are more prominent within hierarchy and market controls, as they emphasise control.

The upper echelons theory notion linking TMT age, organisation tenure and team tenure with performance has received considerable support (Bell et al., 2011; Hambrick, 2007; Sturman, 2003). Younger TMTs have been found to be more open to strategic change and take risks while older TMTs become inflexible and avoid risky decisions (Wiersema and Bantel, 1992). Within the CVF, adhocracies have been characterised as agile and risk-taking while hierarchies are cautious and value stability (Hartnell et al., 2011; Zammuto and O'Connor, 1992). Thus, adhocracy control should have younger TMTs and hierarchy control older TMTs.

Long organisation tenure has been shown to increase the TMTs resistance to change and preserve organisational status quo (Boeker, 1997). Long tenures should be common with hierarchy control as it attempts to maintain existing structures (O'Neill and Quinn, 1993). In turn, long organisation tenure is a prerequisite for clan control (Baliga and Jaeger, 1984). On the other hand, long organisation tenures can adversely affect the agility of adhocracy control and the environmental scanning of market control (Abebe, 2010; Hartnell et al., 2011). This suggests TMTs of clan and hierarchy organisations display longer organisation tenures than TMTs of adhocracies and market organisations.

Although TMTs might not function as real teams, they have been found to integrate their behaviour with increasing team tenure (Hambrick, 2007). Clan control encourages teamwork, personnel development and empowerment and would benefit from more team-like behaviour (Hartnell et al., 2011). In contrast, market control cold exhibit short-team tenures as it stresses achievement or short-term results and control is based on agreed outputs (Hartnell et al., 2011; Ouchi, 1979). 


\subsection{Hypotheses development}

Miles and Snow (1978) suggest three viable strategies management can pursue by designing and implementing the appropriate organisation and controls to be effective and competitive. Consequently, the strategy-performance link has received substantial interest in the strategic management research and numerous studies have found support for equal performance and effectiveness of the viable business strategies (Blackmore and Nesbitt, 2013; Conant et al., 1990; Woodside et al., 1999). There is also evidence of differing performance between the viable strategies (Hambrick, 1983; Parnell and Wright, 1993; Snow and Hrebiniak, 1980). Zahra and Pearce (1990) indicate firm size, environmental attributes and fit between strategy type and implementation confound the strategy-performance link. Also, Miles and Snow (1978) point out the increased cost to analysers operating in two domains compared to pure defenders or prospectors operating in a single domain.

Successful organisations continually monitor their environment and adapt to the detected changes. Miles and Snow (1978) separate this continuous process or adaptive cycle into three major problems management must solve: entrepreneurial, engineering and administrative problems. The entrepreneurial problem focuses on the definition of the organisation's product-market domain, the engineering problem solves the choice of technologies and processes and the administrative problem creates and maintains a system of organisational structure and control (Conant et al., 1990). Defender type organisations concentrate on the engineering tasks when striving for efficiency, while prospector organisations commit more resources to the entrepreneurial tasks of monitoring markets and trends (Conant et al., 1990). Analysers due to their dual nature are more balanced. Therefore, all three strategies have differing administrative problems and their solutions.

How the organisation solves the administrative problem is crucial for firm performance. The administrative problem involves the selection, justification and development of the organisation structure and processes when attempting to coordinate and implement its strategies (Conant et al., 1990; Shortell and Zajac, 1990). Management controls are the processes and mechanisms managers use to influence the behaviour of individuals and groups towards the objectives and goals (Flamholtz et al., 1985). These control processes and mechanisms are not used in isolation; instead, they are combined and used together as management control systems (Malmi and Brown, 2008). The four MCS types identified in Section 2.2 represent different approaches to how organisations solve the administrative problem.

According to Miles and Snow (1978, p. 48), the administrative problem of defenders is "how to maintain strict control of the organization in order to ensure efficiency". Organisations utilising management controls focusing on control and stability would be more efficient and show better performance. Both hierarchy and market MCS types emphasise stability and control, while hierarchies underscore an internal view of the organisation and markets an external view (Quinn and Rohrbaugh, 1983). Therefore, a hierarchy or market MCS would be better for an organisation following a defender strategy. The following hypothesis can be stated:

H1. A defender strategy performs better with hierarchy or market MCS types than clan or adhocracy MCS types.

The administrative problem of prospectors is "how to facilitate and coordinate numerous and diverse operations" (Miles and Snow, 1978, p. 66). Prospectors strive to constantly add and change their products and services calling for innovation and flexibility (Shortell and Zajac, 1990). Clan and adhocracy MCS types value flexibility and individuality in their structure while clan has an internal and adhocracy an external view (Quinn and Rohrbaugh, 1983). This suggests a clan or adhocracy MCS would be better for an organisation following a prospector strategy. A second hypothesis can be stated:

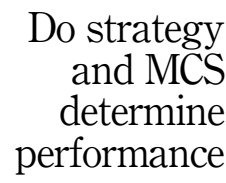

665 
IJPPM

72,3

\section{6}

H2. A prospector strategy performs better with clan or adhocracy MCS types than hierarchy or market MCS types.

Analysers try to balance the two domains they operate in. In the stable product-market domain they seek efficiency while in the turbulent product-market domain they innovate and seek new opportunities (Shortell and Zajac, 1990). Their administrative problem is to differentiate and integrate the organisations structure and processes between the two domains (Miles and Snow, 1978). Therefore, analysers would use management controls that signal control and stability in the stable domain and flexibility and individuality in the turbulent domain. In this light, analysers can apply various MCS types with acceptable performance. This leads to the third hypothesis:

H3. An analyser strategy can perform equally well with all MCS types.

Return on assets (ROA) is a commonly used measure of organisation performance (Kihn, 2010). ROA measures how successfully the firm has utilised its assets to generate profits (net profit plus interest and finance costs) irrespective of the financing of those assets, whether it is equity or debt (Selling and Stickney, 1989). Thus, ROA can also be applied to various types of organisations in different industries as all organisations strive to acquire a share of the limited amount of capital in society (Kihn, 2010; Selling and Stickney, 1989).

\section{Research methodology}

\subsection{Data}

The sample was obtained from firms listed in the NASDAQ OMX Helsinki stock exchange during 2008-2015 including firms in the basic materials, consumer goods, consumer services, industrials and technology industries. Financials, health care, utilities and oil and gas industries were omitted as their financial structure or business differs markedly from the sample. Two firm were omitted as outliers based on Euclidian distance (Hair et al., 2015) and eight firms were omitted due to missing data leaving 80 firms with 621 firm-years of data. After calculation of the strategy construct and the four organisation-level MCS types, the sample consisted of 391 firm-years of data. Demographic data for the sample is presented in Table 1.

The financial data used in this study was obtained from the Voitto + company information database published by Asiakastieto Group and the firms' annual reports. Information on the TMTs was obtained from the published and audited annual reports of the firms. Additional information was obtained from stock exchange releases, firm Internet pages and TMT member LinkedIn profiles. The TMT was defined as the team the firm reported in their annual report. It was thus conceptualised as a real team identified by itself and outsiders as a team (Senior and Swailes, 2004).

\subsection{Methods and measures}

Following Jukka and Pellinen (2020), TMT size, firm size, functional backgrounds, age, firm tenure and TMT team tenure were used to cluster the sample and differentiate the four organisation-level MCS types. First, hierarchical cluster analysis applying squared Euclidian distance as similarity measure and Ward's method as clustering algorithm was used to produce a full set of cluster solutions. Increase in heterogeneity measured as the agglomeration coefficient was used to determine the number of clusters (Hair et al., 2015). The cluster solution was further optimised using non-hierarchical K-means clustering as it allows the reassignment of cases to other clusters while minimising heterogeneity (Hair et al., 2015). To avoid variables with large ranges getting more weight in defining the cluster solution and dominating the result, the variables were standardised using Z-scores (Ketchen and Shook, 1996). 


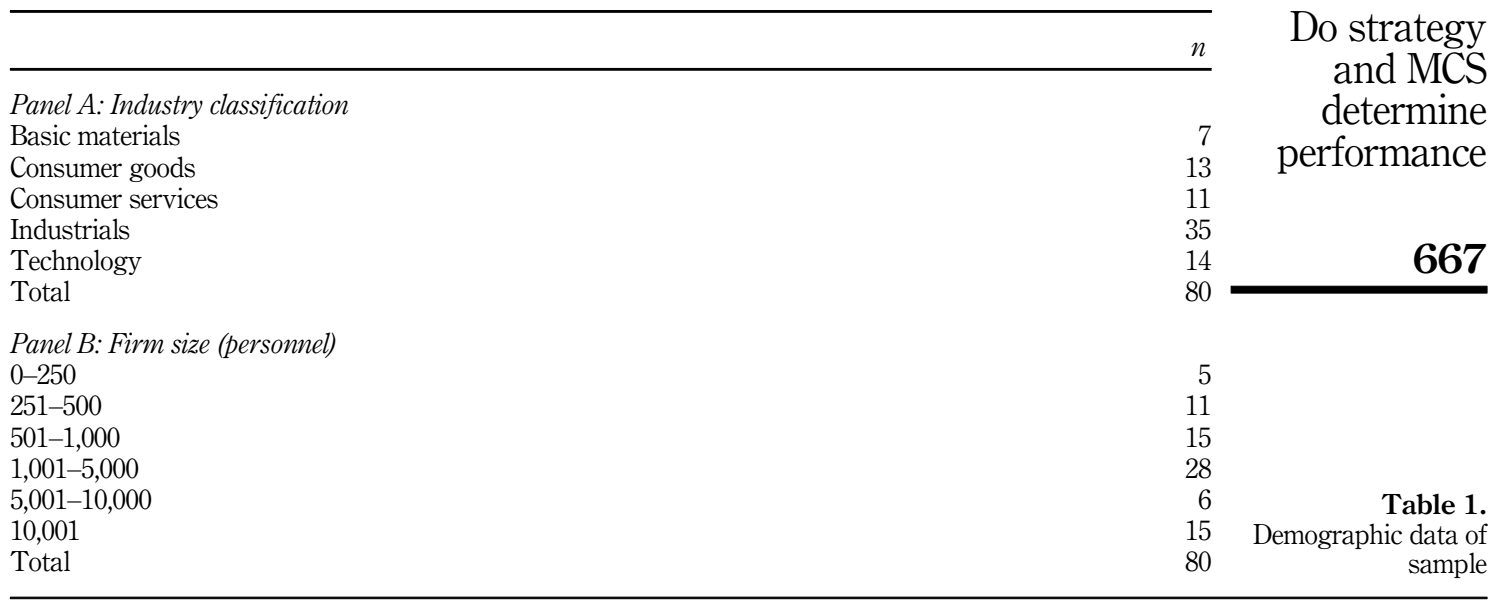

TMT size was the number of persons in the team. Firm size was measured as the mean number of employees during a fiscal year.

The functional background variables were calculated as the share of managers with the corresponding background in the TMT. Consistent with prior studies (Abebe, 2010; Hambrick and Mason, 1984), TMT functional backgrounds were categorised as output, throughput and peripheral functions. Output functions include marketing, sales and R\&D. They emphasise growth and search for new opportunities and markets. Throughput functions seek to improve the efficiency of the transformation process and include production, process engineering and accounting. Peripheral functions (e.g. law, personnel, finance) are not directly involved with the firm's core activities. A fourth category, general management, was added as not all managers have specific functional backgrounds, but instead have broader general management backgrounds (e.g. division heads; Biemann and Wolf, 2009).

TMT age, firm tenure and team tenure were measured as simple averages of team member age and tenures for each fiscal year.

Prior to determining the viable business strategies, the reactor strategies were identified from the sample. A reactor strategy is unviable and unprofitable (Hambrick, 1983; Miles and Snow, 1978) resulting in low or negative ROA. Firms with two negative ROA values during a three-year period were deemed reactors during this period. These cases were omitted when ranking the viable strategies. A single negative ROA value was considered a chance and seen as a viable strategy case.

The viable business strategy of the firms was measured with a composite strategy measure based on variables from prior studies (Bentley et al., 2013; Ittner et al., 1997) that reflect different aspects of the underlying business strategy with high values representing firms following prospector strategies, low values defender strategies and analysers between them. Similar to Bentley et al. (2013), the following variables were used in the strategy construct: (1) the ratio of research and development to sales, (2) growth of sales, (3) the ratio of employees to sales, (4) the ratio of sales to operating costs, (5) variation in number of employees and (6) the ratio of net property, plant and equipment (NPPE) to total assets.

The ratio of research and development to sales is an indicator for the firms tendency to seek new products (Ittner et al., 1997; Thomas and Ramaswamy, 1996). Prospectors are 
IJPPM

72,3

668

involved in more innovative activities inducing higher expenditure in research and development. Growth of sales proxies the firm's growth and investment opportunities with prospectors expected to show higher growth than defenders (Bentley et al., 2013; Ittner et al., 1997). The ratio of employees to sales measures the firm's ability to produce and distribute goods efficiently. As defender strategies focus on efficiency, defenders are expected to have fewer employees than prospectors (Ittner et al., 1997; Thomas and Ramaswamy, 1996). Bentley et al. (2013) used the ratio of selling, general and administrative expenses (SG\&A) to sales as indicator for marketing. Due to unavailability of SG\&A, this was substituted with the ratio of sales to operating costs as firms following prospector strategies can command higher prices (Balsam et al., 2011). Organisational stability concerning the length of employee tenure and turnover is proxied by the variation in number of employees (Bentley et al., 2013; Higgins et al., 2015). Prospectors tend to have shorter tenures and higher turnover leading to higher variation (Higgins et al., 2015). Bentley et al. (2013) measured variation as standard deviation, but this was replaced with the coefficient of variation to make comparison of small and large firms possible (Cramer and Howitt, 2004). The ratio of NPPE to total assets measures the capital intensity and focus on production assets with defenders expected to score higher (Bentley et al., 2013; Higgins et al., 2015).

Following earlier studies (Bentley et al., 2013; Ittner et al., 1997) the variables were averaged over a four-year rolling period (the firm-year and three prior years). To construct the strategy measure, within each industry class, each of the six variables were sorted in descending order and ranked by forming quintiles giving firms in the highest quintile a score of 5 , the second highest a score of 4 and so on. Firms in the lowest quintile received a 1 . The scoring was inverted for the NPPE to total assets ratio as defenders were expected to get higher results. Then for each firm the ranking scores were summed across the six variables giving a maximum score of 30 and a minimum score of 6 . Finally, firms with scores $6-13$ were considered defenders, 14-22 analysers and 23-30 prospectors (Bentley et al., 2013).

Firm performance was measured as ROA. It was calculated as how much the business generated profit for the average assets during the financial year. Profit was net profit plus interest and finance costs. Average assets were the average of balance sheet total for the current and previous years.

\section{Results}

The means, standard deviations and correlations for the sample are shown in Table 2. The correlation matrix shows conceivable associations between the variables and the highest correlation was -0.64 . The pairwise correlations were below the generally accepted limit of 0.70, indicating there were no concerns with multicollinearity (Hair et al., 2015).

Using a combination of hierarchical and non-hierarchical clustering methods the sample was separated into groups representing differing organisation-level MCS types (Jukka and Pellinen, 2020). Cluster analysis is commonly used to group similar objects into clusters, which differ from objects in the other clusters (Hair et al., 2015). First, hierarchical cluster analysis was used to create a full set of cluster solutions. Increase in heterogeneity measured by the agglomeration coefficient (Hair et al., 2015) supported a four-cluster solution and this was further optimised using non-hierarchical $K$-means clustering which reassigns observations into other clusters in order to minimise heterogeneity (Hair et al., 2015). Software generated seed points were used to create a four-cluster solution with 136, 158, 100 and 227 cases in the clusters, see Table 3 . Different seed points for the $K$-means clustering were used to test the robustness and validity of the solution. As a result, $92.2 \%$ of the cases were grouped in the correct cluster suggesting a very stable solution (Hair et al., 2015).

The four clusters in the cluster solution were interpreted based on the clustering variables. Jukka and Pellinen (2020) suggested the identified four clusters proxied the underlying MCS 


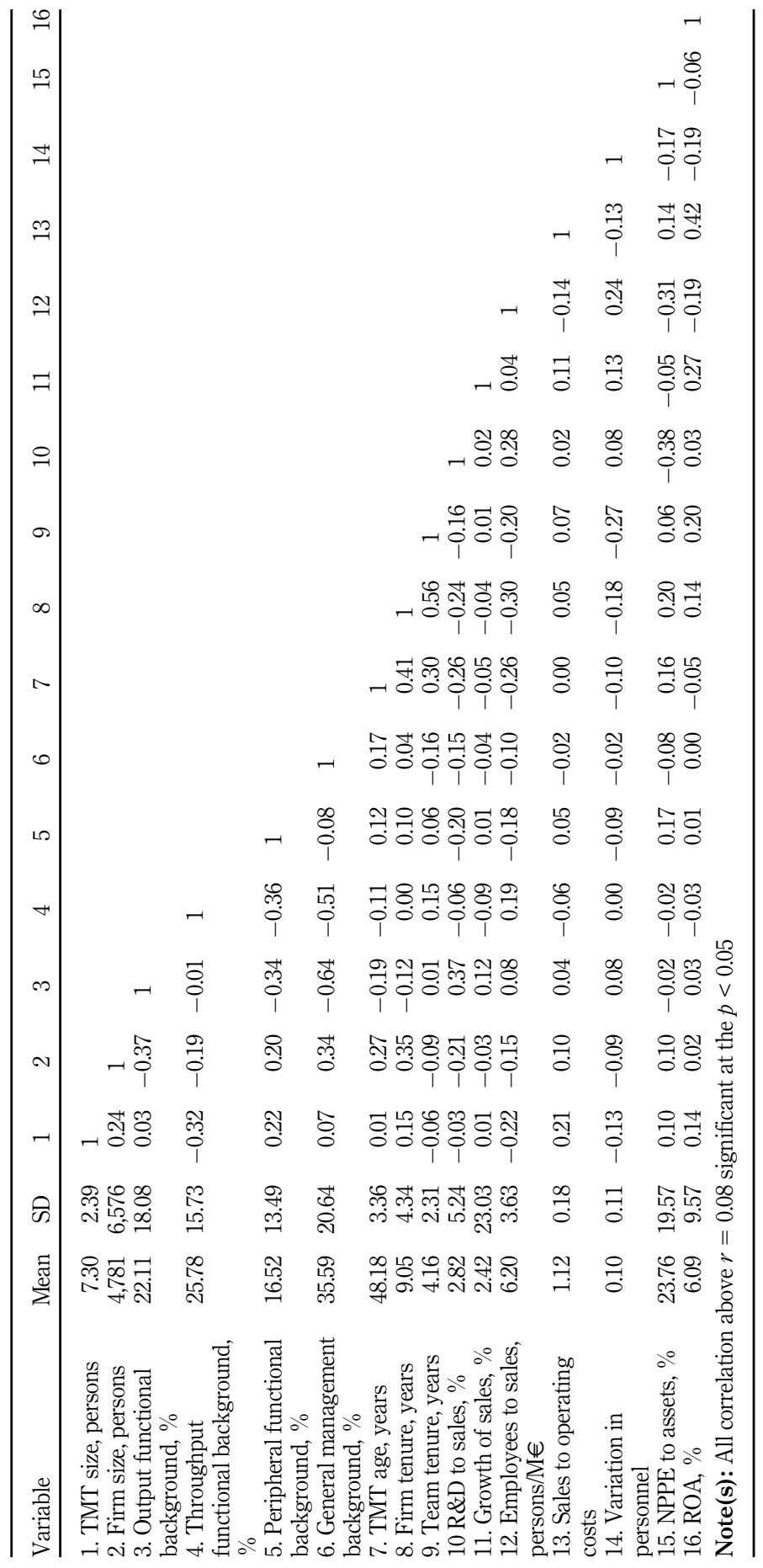
Do strategy and MCS determine performance
669

Table 2. Descriptive statistics and Pearson correlations $(n=621)$ 


\begin{tabular}{|c|c|c|c|c|c|}
\hline $\begin{array}{l}\text { IJPPM } \\
72,3\end{array}$ & Cluster & $\begin{array}{c}1 \\
\text { Clan } \\
\end{array}$ & $\begin{array}{c}2 \\
\text { Adhocracy }\end{array}$ & $\begin{array}{c}3 \\
\text { Market }\end{array}$ & $\begin{array}{c}4 \\
\text { Hierarchy } \\
\end{array}$ \\
\hline \multirow[b]{5}{*}{670} & TMT size, persons & 7.54 & 6.84 & 5.11 & 8.44 \\
\hline & Firm size, persons & 3,372 & 1,419 & 1,319 & 9,495 \\
\hline & Output functional background, $\%$ & 26.83 & 38.43 & 14.6 & 11.21 \\
\hline & Throughput functional background, \% & 28.7 & 24.76 & 45.75 & 15.83 \\
\hline & Peripheral functional background, $\%$ & 22.23 & 12.68 & 5.51 & 20.65 \\
\hline \multirow{6}{*}{$\begin{array}{l}\text { Table } 3 \text {. } \\
\text { Results of the } K \text {-means } \\
\text { clustering }(n=621)\end{array}$} & General management background, \% & 22.22 & 24.13 & 34.14 & 52.27 \\
\hline & TMT age, years & 49.56 & 45.58 & 47.95 & 49.26 \\
\hline & Firm tenure, years & 12.87 & 5.67 & 7.62 & 9.75 \\
\hline & Team tenure, years & 7.06 & 2.84 & 3.93 & 3.42 \\
\hline & Cases & 136 & 158 & 100 & 227 \\
\hline & $\%$ & 21.9 & 25.4 & 16.1 & 36.6 \\
\hline
\end{tabular}

types in place. The first cluster identified as clan MCS type was characterised by a large TMT with diverse functional backgrounds suggesting a tendency towards teamwork, participation and human resource development (Hartnell et al., 2011). Also, long firm and team tenures found in this cluster have been noted to promote clan control (Baliga and Jaeger, 1984).

Firms in the second cluster were characterised as using adhocracy type control. The small organisations and TMTs suggested flat, adaptive organisation structures that are flexible and adaptive to environmental changes (Villalba, 2006). A large part of the TMT had output functional backgrounds suggesting increased environmental scanning and searching for growth opportunities (Cho, 2006). Managers with peripheral functional backgrounds were low in this cluster. They are not involved with the firm's core activities and may not enhance adaptability, creativity and agility of these organisations (Hartnell et al., 2011). The young and short-tenured TMTs also supported a view of agility and innovation seeing that increasing age promotes risk avoidance (Wiersema and Bantel, 1992) and long-tenure inflexibility and less environmental scanning (Abebe, 2010).

The third cluster of firms were characterised by a small organisation and small TMT with a large share of managers with general management backgrounds suggesting these firms rely on competent governance from experienced managers (Biemann and Wolf, 2009). The short firm and team tenures of TMTs denoted a willingness to change or initiate new strategies (Wiersema and Bantel, 1992). These are characteristic for a directive and goaloriented leadership exerting market type control (Hartnell et al., 2011; Zammuto and O'Connor, 1992). Goal-oriented market type control also benefits from the high share of top managers with throughput functional backgrounds, i.e. production, process engineering and accounting, as efficiency and productivity are pursued (Hartnell et al., 2011; Quinn and Rohrbaugh, 1983).

Firms in the fourth cluster were large and had the largest TMTs. Large organisations become more bureaucratic and hierarchical as their size increases inducing hierarchical controls within the organisation (Baliga and Jaeger, 1984; Mintzberg, 1996b). The TMTs had the highest share of managers with general management backgrounds and long firm tenures. These managers have ascended within the organisation in general management positions gaining the experience needed to control and coordinate large organisations (Biemann and Wolf, 2009). The lack of outward scanning managers with output functional backgrounds suggested emphasis on internal control and coordination in hierarchical type of control.

Table 4 provides descriptive statistics for the strategy construct and its raw components. In the first step, $65(16.6 \%)$ reactor cases were identified. Next, the viable business strategies were identified using the composite strategy measure. Consistent with expectations, firms 
following defender, analyser and prospector strategies had significantly different $(p<0.05)$ means in the composite strategy measure and all its six components. Although, all these strategies are viable (Miles and Snow, 1978) the share of defenders and prospectors was only 13 and $12 \%$ respectively while analysers made up $75 \%$. Earlier research (Bentley et al., 2013; Higgins et al., 2015; Lim et al., 2018) have reported 5-8\% of defenders and prospectors. The difference was mostly due to the use of the coefficient of variation as a measure for variation in personnel in this study. In unreported analysis when using standard deviation as a measure for variation in personnel the share of defenders and prospectors fell to $8 \%$ being comparable with earlier research. Standard deviation was highly correlated with the mean biasing the results and supporting use of the coefficient of variation.

One-way analysis of variance (ANOVA) was conducted to explore the impact of MCS type on effectiveness of different business strategies. To test the hypotheses the mean ROA was calculated for each MCS type for the different business strategies and compared using planned contrasts and post hoc multiple comparison procedures (MCP) (Belhekar, 2016; Howell, 2008). Levene's test revealed $(p<0.01)$ the group variances were unequal and group sizes differed for the analysers, mean of the viable strategies and reactors, making the Welch $F$-statistic and the Games-Howell post hoc test appropriate choices (Howell, 2008). The groups in defender and prospector strategies did not differ significantly and were analysed using the omnibus $F$-statistic. Table 5 shows the results of the analysis used to compare the means.

The first hypothesis suggested a defender strategy performs better with hierarchy or market MCS types than clan or adhocracy MCS types. There was a significant difference in ROA for the four MCS types $(F(3,39)=2.45, p=0.078)$. The planned contrasts test showed ROA was significantly $(p=0.087)$ higher for hierarchy $(M=4.60, \mathrm{SD}=3.19)$ and market MCS types $(M=8.89, \mathrm{SD}=5.56)$ than for clan $(M=3.90, \mathrm{SD}=4.58)$ and adhocracy MCS types $(M=3,59, \mathrm{SD}=4.15$. These results support hypothesis 1 .

The second hypothesis stated that a prospector strategy performs better with clan or adhocracy MCS types than hierarchy or market MCS types. The ANOVA detected a significant difference in ROA between the four MCS types $(F(3,36)=3.18, p=0.036)$. The planned contrasts test indicated a significantly $(\phi=0.021)$ higher ROA for clan $(M=17.84, \mathrm{SD}=4.36)$ and adhocracy MCS types $(M=13.95, \mathrm{SD}=13.45)$ than market $(M=9.31, \mathrm{SD}=4.60)$ and hierarchy types $(M=5.48, \mathrm{SD}=3.56)$. Hypothesis 2 is thus supported.

The third hypothesis suggested an analyser strategy can perform equally well with all MCS types. The results showed all MCS types achieved positive ROA for analyser strategies. The ANOVA indicated a significant difference between the MCS types $(F(3,100.81)=3.63$, $p=0.016)$, but post hoc analysis revealed only a significant difference between clan $(M=10.87$, $\mathrm{SD}=8.47)$ and hierarchy $(M=6.93, \mathrm{SD}=4.15)$ MCS types. Adhocracy and market MCS types did not differ significantly from the other MCS types. Thus, with only one significant difference, hypothesis 3 is partly supported.

\begin{tabular}{|c|c|c|c|c|c|c|}
\hline & Total & Defender & Analyser & Prospector & Reactor & \\
\hline Strategy construct & 15.01 & 11.91 & 18.07 & 24.15 & & \\
\hline R\&D to sales, $\%$ & 2.78 & 0.51 & 2.71 & 6.03 & 2.53 & \\
\hline Growth of sales, $\%$ & 3.38 & 0.62 & 3.59 & 16.02 & -3.34 & \\
\hline Employees to sales, persons/M€ & 6.03 & 4.13 & 5.64 & 8.27 & 7.33 & \\
\hline Sales to operating costs & 1.11 & 1.09 & 1.13 & 1.14 & 1.01 & \\
\hline Variation in personnel & 0.12 & 0.06 & 0.10 & 0.23 & 0.18 & \\
\hline NPPE to assets, $\%$ & 0.23 & 0.38 & 0.21 & 0.12 & 0.25 & Table 4. \\
\hline $\mathrm{ROA}, \%$ & 5.75 & 5.10 & 8.26 & 11.03 & -6.46 & Descriptive statistics of \\
\hline Cases & 391 & 43 & 243 & 40 & 65 & the strategy \\
\hline$\%$ & & 11.0 & 62.1 & 10.2 & 16.6 & construct $(n=391)$ \\
\hline
\end{tabular}

Do strategy and MCS determine performance 


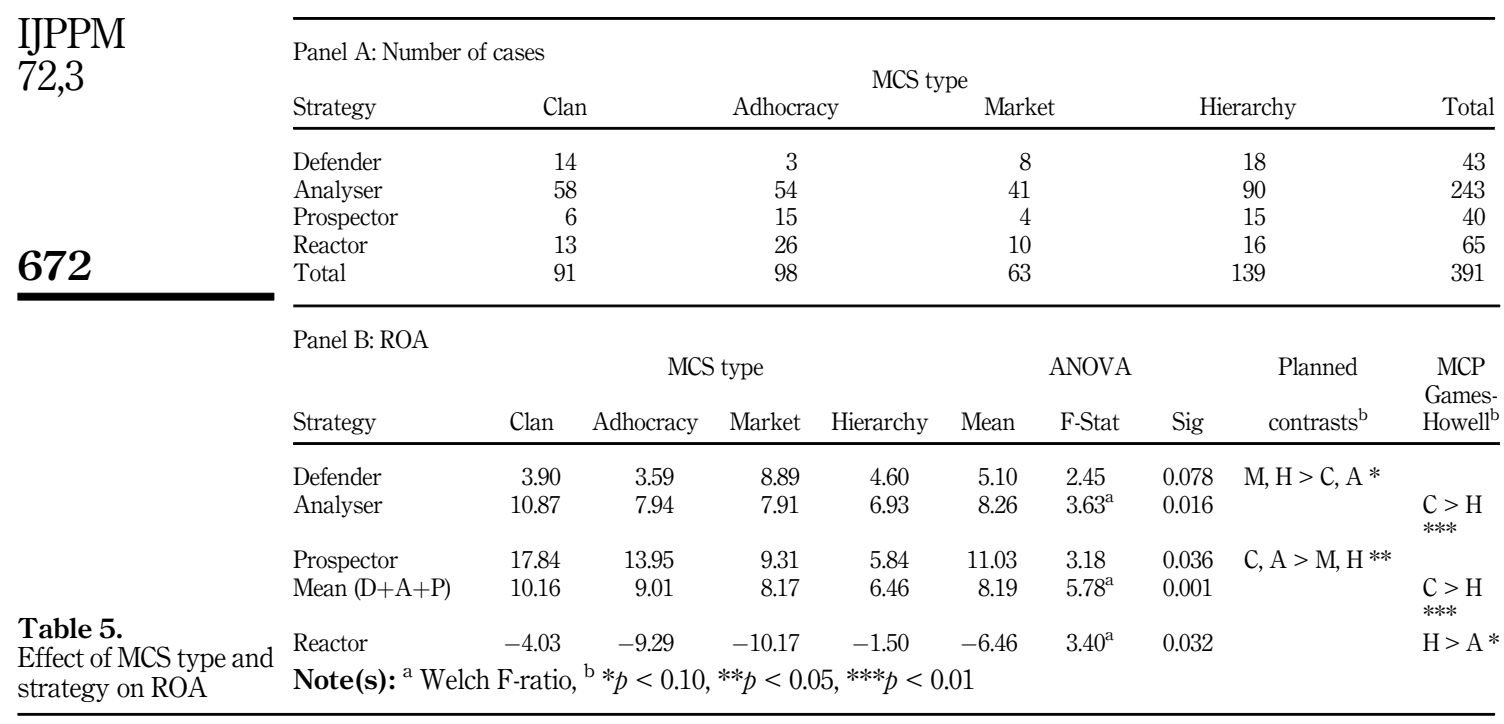

\section{Discussion}

Management control systems are the collection of control processes and mechanisms management uses to reach their organisation's predetermined objectives and goals. The objectives and goals are a result of the organisations strategy and prior literature suggests strategy and MCS should be aligned to reach optimal performance. To further our understanding of the relationship between business strategy, MCS and performance, this study examined the alignment of business strategy with organisation-level MCS types and its effect on performance.

This study set out with the aim of assessing if a certain type MCS works better with a particular business strategy. Miles and Snow (1978) suggest three viable strategies that should all be equally effective if implemented successfully. The results of this study showed a defender business strategy brought about better performance when using hierarchy or market type MCS compared to using clan or adhocracy types. Similarly, the use of clan or adhocracy type MCS produced better performance than market or hierarchy type MCS when pursuing a prospector business strategy. These results suggest a defender business strategy performs better when applying a control oriented MCS type and a prospector business strategy performs better when applying a flexibility oriented MCS type. Supporting these findings, the CVF also links control, stability and efficiency with market and hierarchy control and development, flexibility and adaption with clan and adhocracy control (Quinn and Rohrbaugh, 1983). Similarly, Henri (2006b) also found managers used management controls differently at the opposing ends of the CVF flexibility-control continuum. He found firms displaying flexibility values used more interactive controls and performance measures to achieve more interaction and communication, whereas firms displaying control values used fewer interactive controls and measures and tight control of operations. These results suggest that for a strategy to be viable it should be aligned with a certain type of MCS, where the controls match the requirements of the business strategy. The mismatch of MCS type and business strategy may explain the differences in performance between the viable strategies in prior research (Hambrick, 1983; Parnell and Wright, 1993; Snow and Hrebiniak, 1980; Zahra and Pearce, 1990).

It was also hypothesised that an analyser business strategy can perform well with all MCS types. The results showed that all MCS types were effective with an analyser strategy 
producing a positive ROA. The results suggest that analysers can use varied types of management controls to reach an acceptable result when balancing their stable and turbulent product-market domains. Also, the intensity of the distinct management controls within each MCS type presumably adjust depending on how management attempts this balancing. Prior studies have noted firms apply and benefit from different management practices and accounting techniques when pursuing low cost or differentiation strategies (Chenhall and Langfield-Smith, 1998). It could also be possible that analysers combine different MCS types to be used in the different product-market domains (Zahra and Pearce, 1990). Unfortunately, the results of this study do not shed light on the possible combination of MCS types as the sample was split into four distinct groups.

The results also provide insight into the administrative problem of the adaptive cycle facing management continuously. Prior research suggests that defender type organisations focus on the engineering problems of the adaptive cycle when striving for efficiency and good performance, while prospector organisations focus on the entrepreneurial problems of monitoring markets and trends (Conant et al., 1990). In this light, the results suggest that the different MCS types are not all suitable for solving both the engineering and the entrepreneurial problems. Market and hierarchy MCS types are more suited to tackle the engineering problems while clan and adhocracy MCS types fair better with the entrepreneurial problems.

This research contributes to the management control and strategy literature in several ways. First, the results suggest the organisation-level MCS type, or how control is addressed in its entirety at the organisational level, should be aligned with the organisation's business strategy to reach the organisation's predetermined objectives and goals. The need for aligning the MCS type and business strategy is more pronounced when pursuing defender or prospector strategies, while the choice of MCS type seems to be less critical with analysers operating in two product-market domains. Second, the results also provide new insights of the administrative problem in Miles and Snow's (1978) adaptive cycle. The MCS types reflect how management solves the administrative problem and each MCS type may be better suited to solve either the entrepreneurial or the engineering problem. The administrative problem has received limited interest and prior research has focused on individual properties of the top management, organisation, structure, coordination or performance measurement (Thomas and Ramaswamy, 1996). As a third contribution, this study demonstrates the use of archival accounting and TMT data as proxies for organisation-level MCS archetypes and business strategies to study the MCS - business strategy link. Extant research has mostly relied on personal interviews and surveys of informants (Otley, 2016).

\subsection{Managerial implications}

Management is tasked with developing a business strategy for their organisation how it will compete and position itself in their markets (Langfield-Smith, 1997). Management selects and uses a collection of control processes and mechanisms forming the MCS to reach their predetermined objectives and goals (Malmi and Brown, 2008). Prior studies suggest the MCS should be aligned with the business strategy as a misfit would impair performance (Chenhall, 2003; Gani and Jermias, 2012). Although the defender, analyser and prospector strategies are all viable (Miles and Snow, 1978), the results of this study suggest aligning strategy and MCS improves performance. A defender strategy could benefit from control-oriented market or hierarchy MCS types and a prospector strategy from flexibility-oriented clan or adhocracy MCS types. Although a clan MCS type performed best with an analyser strategy, all the other MCS types gave acceptable performance.

The results also provide knowledge about matching managers with the business strategy and the MCS. The upper echelons theory (Hambrick and Mason, 1984) has been widely used to
Do strategy and MCS determine performance

673 
IJPPM 72,3

\section{4}

explore the effect of top management on organisation strategy and performance. According to the upper echelons theory the top executives past experiences, values and personalities are reflected in their strategic decision-making and the following results (Hambrick, 2007). The TMTs of the different MCS types exhibited differing functional backgrounds, ages and tenures. The results suggest top management with extensive general management experience successfully implemented a defender strategy with a market or hierarchy MCS type, while top management with diverse backgrounds was better implementing a prospector strategy using a clan or adhocracy type MCS. Prior studies have also noted differences in the backgrounds of top management pursuing the different strategies (Snow and Hrebiniak, 1980; Thomas and Ramaswamy, 1996). These findings suggest that the composition of the TMT should match the intended MCS type and business strategy.

\subsection{Limitations and directions for future research}

While the study gave new information on the relationship between business strategy, MCS type and performance, there are limitations to this study. Although cluster analysis is appropriate to group objects based on their characteristics, it can be criticised for being too effective and always generating clusters even if there is no rational basis for the result. The cluster solution should be theoretically supported to bear any relevance. Although the cluster solution results can be to some extent confirmed using stopping rules and using different seed points, cluster analysis does not test the significance of the presented result. While the results were very stable, the results are not conclusive and there is need to verify the different MCS types.

Although substantial effort was done to get a representative and generalisable sample, the data may have shortcomings. The sample consisted of firms from six industries over a period of 8 years, but it was limited to a single country. The strategy construct was calculated as average over 4 years limiting the sample in effect to 5 years. Future studies should collect longitudinal data over extended periods to study the dynamics and development of the relationship between business strategy, MCS type and performance.

Business strategy was measured as a strategy construct based on past financial data. This measure captures the realised rather than the intended strategy (Thomas and Ramaswamy, 1996) making comparison to extant survey-based studies measuring intended strategies difficult. There is a need to see how financial data and survey-based strategy measures compare. Despite these limitations, the present study has provided additional evidence on the relationship between business strategy, MCS type and performance.

\section{References}

Abebe, M.A. (2010), “Top team composition and corporate turnaround under environmental stability and turbulence", Leadership and Organization Development Journal, Vol. 31 No. 3, pp. 196-212.

Baliga, B.R. and Jaeger, A.M. (1984), "Multinational corporations: control systems and delegation issues", Journal of International Business Studies, Vol. 15 No. 2, pp. 25-40.

Balsam, S., Fernando, G.D. and Tripathy, A. (2011), "The impact of firm strategy on performance measures used in executive compensation”, Journal of Business Research, Vol. 64 No. 2, pp. 187-193.

Bedford, D.S. and Malmi, T. (2015), “Configurations of control: an exploratory analysis”, Management Accounting Research, Vol. 27 No. 1, pp. 2-26.

Belhekar, V.M. (2016), Statistics for Psychology Using R, Sage Publications, London.

Bell, S.T., Villado, A.J., Lukasik, M.A., Belau, L. and Briggs, A.L. (2011), "Getting specific about demographic diversity variable and team performance relationships: a meta-analysis", Journal of Management, Vol. 37 No. 3, pp. 709-743. 
Bentley, K.A., Omer, T.C. and Sharp, N.Y. (2013), "Business strategy, financial reporting irregularities, and audit effort", Contemporary Accounting Research, Vol. 30 No. 2, pp. 780-817.

Biemann, T. and Wolf, J. (2009), "Career patterns of top management team members in five countries: an optimal matching analysis", The International Journal of Human Resource Management, Vol. 20 No. 5, pp. 975-991.

Blackmore, K. and Nesbitt, K. (2013), "Verifying the Miles and Snow strategy types in Australian small- and medium-size enterprises", Australian Journal of Management, Vol. 38 No. 1, pp. 171-190.

Boeker, W. (1997), "Strategic change: the influence of managerial characteristics and organizational growth", Academy of Management Journal, Vol. 40 No. 1, pp. 152-170.

Büschgens, T., Bausch, A. and Balkin, D.B. (2013), "Organizational culture and innovation: a metaanalytic review", Journal of Product Innovation Management, Vol. 30 No. 4, pp. 763-781.

Cameron, K. and Lavine, M. (2006), Making the Impossible Possible: Leading Extraordinary Performance: The Rocky Flats Story, Berrett-Koehler Publishers, San Francisco.

Certo, S.T., Lester, R.H., Dalton, C.M. and Dalton, D.R. (2006), "Top management teams, strategy and financial performance: a meta-analytic examination", Journal of Management Studies, Vol. 43 No. 4, pp. 813-839.

Chenhall, R.H. (2003), "Management control systems design within its organizational context: findings from contingency-based research and directions for the future", Accounting, Organizations and Society, Vol. 28 No. 2, pp. 127-168.

Chenhall, R.H. and Langfield-Smith, K. (1998), "The relationship between strategic priorities, management techniques and management accounting: an empirical investigation using a systems approach", Accounting, Organizations and Society, Vol. 23 No. 3, pp. 243-264.

Cho, T.S. (2006), "The effects of executive turnover on top management team's environmental scanning behavior after an environmental change", Journal of Business Research, Vol. 59 Nos 10-11, pp. 1142-1150.

Conant, J.S., Mokwa, M.P. and Varadarajan, P.R. (1990), "Strategic types, distinctive marketing competencies and organizational performance: a multiple measures-based study", Strategic Management Journal, Vol. 11 No. 5, pp. 365-383.

Cooper, R.B. and Quinn, R.E. (1993), "Implications of the competing values framework for management information systems", Human Resource Management, Vol. 32 No. 1, pp. 175-201.

Cramer, D. and Howitt, D. (2004), The Sage Dictionary of Statistics, Sage Publications, London.

Ferreira, A. and Otley, D. (2009), "The design and use of performance management systems: an extended framework for analysis", Management Accounting Research, Vol. 20 No. 4, pp. 263-282.

Flamholtz, E.G. Das, T.K. and Tsui, A.S. (1985), "Toward an integrative framework of organizational control", Accounting, Organizations and Society, Vol. 10 No. 1, pp. 35-50.

Gani, L. and Jermias, J. (2012), "The effects of strategy-management control system misfits on firm performance", Accounting Perspectives, Vol. 11 No. 3, pp. 165-196.

Hair, J.F., Black, W.C., Babin, B.J. and Anderson, R.E. (2015), Multivariate Data Analysis, 7th ed., Dorling Kindersley, Delhi.

Haleblian, J. and Finkelstein, S. (1993), "Top management team size, CEO dominance, and firm performance: the moderating roles of environmental turbulence and discretion", Academy of Management Journal, Vol. 36 No. 4, pp. 844-863.

Hambrick, D.C. (1983), "Some tests of the effectiveness and functional attributes of Miles and Snow's strategic types", Academy of Management Journal, Vol. 26 No. 1, pp. 5-26.

Hambrick, D.C. (2007), "Upper echelons theory: an update", Academy of Management Review, Vol. 32 No. 2, pp. 334-343.
Do strategy
and MCS
determine
performance

675 
IJPPM

72,3

Hambrick, D.C. and Mason, P.A. (1984), "Upper echelons: the organization as a reflection of its top managers", The Academy of Management Review, Vol. 9 No. 2, pp. 193-206.

Hartnell, C.A., Ou, A.Y. and Kinicki, A. (2011), "Organizational culture and organizational effectiveness: a meta-analytic investigation of the competing values framework's theoretical suppositions", Journal of Applied Psychology, Vol. 96 No. 4, pp. 677-694.

Henri, J.-F. (2006a), "Management control systems and strategy: a resource-based perspective", Accounting, Organizations and Society, Vol. 31 No. 6, pp. 529-558.

Henri, J.F. (2006b), "Organizational culture and performance measurement systems”, Accounting, Organizations and Society, Vol. 31 No. 1, pp. 77-103.

Higgins, D., Omer, T.C. and Phillips, J.D. (2015), "The influence of a firm's business strategy on its tax aggressiveness", Contemporary Accounting Research, Vol. 32 No. 2, pp. 674-702.

Howell, D. (2008), "Best practices in the analysis of variance", in Osborne, J. (Ed.), Best Practices in Quantitative Methods, Sage Publications, Thousand Oaks, California, CA, pp. 341-357.

Ittner, C.D., Larcker, D.F. and Rajan, M.V. (1997), "The choice of performance measures in annual bonus contracts", The Accounting Review, Vol. 72 No. 2, pp. 231-255.

Jukka, T. and Pellinen, J. (2020), "Exploring management control system typologies: an organisationlevel view", Journal of Accounting and Organizational Change, Vol. 16 No. 3, pp. 427-445.

Ketchen, D.J. and Shook, C.L. (1996), "The application of cluster analysis in strategic management research: an analysis and critique", Strategic Management Journal, Vol. 17 No. 6, pp. 441-458.

Kihn, L.A. (2010), "Performance outcomes in empirical management accounting research: recent developments and implications for future research", International Journal of Productivity and Performance Management, Vol. 59 No. 5, pp. 468-492.

Kober, R., Ng, J. and Paul, B.J. (2007), "The interrelationship between management control mechanisms and strategy", Management Accounting Research, Vol. 18 No. 4, pp. 425-452.

Koch, M., Forgues, B. and Monties, V. (2017), "The way to the top: career patterns of fortune 100 CEOs", Human Resource Management, Vol. 56 No. 2, pp. 267-285.

Langfield-Smith, K. (1997), "Management control systems and strategy: a critical review", Accounting, Organizations and Society, Vol. 22 No. 2, pp. 207-232.

Lebas, M. and Weigenstein, J. (1986), "Management control: the roles of rules, markets and culture", Journal of Management Studies, Vol. 23 No. 3, pp. 259-272.

Lim, E.K., Chalmers, K. and Hanlon, D. (2018), "The influence of business strategy on annual report readability", Journal of Accounting and Public Policy, Vol. 37 No. 1, pp. 65-81.

Malmi, T. and Brown, D.A. (2008), "Management control systems as a package_opportunities, challenges and research directions", Management Accounting Research, Vol. 19 No. 4, pp. 287-300.

March, J.G. (1991), "Exploration and exploitation in organizational learning”, Organization Science, Vol. 2 No. 1, pp. 71-87.

Miles, R.E. and Snow, C.C. (1978), Organizational Strategy, Structure, and Process, McGraw-Hill, New York, NY.

Mintzberg, H. (1996a), "Five ps for strategy", in Mintzberg, H. and Quinn, J.B. (Eds), The Strategy Process: Concepts, Contexts, Cases, Prentice-Hall International, London, pp. 10-17.

Mintzberg, H. (1996b), "The structuring of organizations", in Mintzberg, H. and Quinn, J.B. (Eds), The Strategy Process: Concepts, Contexts, Cases, Prentice-Hall International, London, pp. 331-349.

Otley, D. (2016), “The contingency theory of management accounting and control: 1980-2014", Management Accounting Research, Vol. 31 No. 1, pp. 45-62.

Ouchi, W.G. (1979), "A conceptual framework for the design of organizational control mechanisms", Management Science, Vol. 25 No. 9, pp. 833-848. 
O'Neill, R.M. and Quinn, R.E. (1993), "Editors' note: application of the competing values framework", Human Resource Management, Vol. 32 No. 1, pp. 1-7.

Parnell, J.A. and Wright, P. (1993), "Generic strategy and performance: an empirical test of the Miles and Snow typology", British Journal of Management, Vol. 4 No. 1, pp. 29-36.

Porter, M.E. (1980), Competitive Strategy, Free Press, New York, NY.

Quinn, R.E. and Rohrbaugh, J. (1983), "A spatial model of effectiveness criteria: towards a competing values approach to organizational analysis", Management Science, Vol. 29 No. 3, pp. 363-377.

Selling, T.I. and Stickney, C.P. (1989), “The effects of business environment and strategy on a firm's rate of return on assets", Financial Analysts Journal, Vol. 45 No. 1, pp. 43-52.

Senior, B. and Swailes, S. (2004), "The dimensions of management team performance: a repertory grid study", International Journal of Productivity and Performance Management, Vol. 53 No. 4, pp. 317-333.

Shortell, S.M. and Zajac, E.J. (1990), "Perceptual and archival measures of Miles and Snow strategic types: a comprehensive assessment of reliability and validity", Academy of Management Journal, Vol. 33 No. 4, pp. 817-832.

Simons, R. (1995), Levers of Control: How Managers Use Innovative Control Systems to Drive Strategic Renewal, Harvard Business School Press, Boston.

Snow, C.C. and Hrebiniak, L.G. (1980), "Strategy, distinctive competence, and organizational performance", Administrative Science Quarterly, Vol. 25 No. 2, pp. 317-336.

Speklé, R.F. (2001), "Explaining management control structure variety: a transaction cost economics perspective", Accounting, Organizations and Society, Vol. 26 Nos 4-5, pp. 419-441.

Strauß, E. and Zecher, C. (2013), "Management control systems: a review", Journal of Management Control, Vol. 23 No. 4, pp. 233-268.

Sturman, M. (2003), "Searching for the inverted U-shaped relationship between time and performance: meta-analyses of the experience/performance, tenure/performance, and age/performance relationships", Journal of Management, Vol. 29 No. 5, pp. 609-640.

Thomas, A.S. and Ramaswamy, K. (1996), "Matching managers to strategy: further tests of the miles and snow typology", British Journal of Management, Vol. 7 No. 3, pp. 247-261.

Treacy, M. and Wiersema, F. (1995), The Discipline of Market Leaders, Addison-Wesley, Reading, Massachusetts, MA.

Tucker, B., Thorne, H. and Gurd, B. (2009), "Management control systems and strategy: what's been happening?”, Journal of Accounting Literature, Vol. 28 No. 1, pp. 123-163.

Villalba, N.V. (2006), "Cost flexibility and firm size: an application to Spanish manufacturing", International Journal of the Economics of Business, Vol. 13 No. 3, pp. 429-446.

Wang, X., Ma, L. and Wang, Y. (2015), "The impact of TMT functional background on firm performance: evidence from listed companies in China's IT industry", Nankai Business Review International, Vol. 6 No. 3, pp. 281-311.

Whitley, R. (1999), "Firms, institutions and management control: the comparative analysis of coordination and control systems", Accounting, Organizations and Society, Vol. 24 Nos 5-6, pp. 507-524.

Wiersema, M.F. and Bantel, K.A. (1992), “Top management team demography and corporate strategic change", Academy of Management Journal, Vol. 35 No. 1, pp. 91-121.

Woodside, A.G., Sullivan, D.P. and Trappey, R.J. (1999), "Assessing relationships among strategic types, distinctive marketing competencies, and organizational performance", Journal of Business Research, Vol. 45 No. 2, pp. 135-146.

$\mathrm{Yu}, \mathrm{T}$. and $\mathrm{Wu}, \mathrm{N}$. (2009), "A review of study on the competing values framework", International Journal of Business and Management, Vol. 4 No. 7, pp. 37-42.

\section{Do strategy and MCS determine performance}


IJPPM

72,3

678
Zahra, S.A. and Pearce, J.A. (1990), "Research evidence on the miles-snow typology", Journal of Management, Vol. 16 No. 4, pp. 751-768.

Zammuto, R.F. and O'Connor, E.J. (1992), "Gaining advanced manufacturing technologies' benefits: the roles of organization design and culture", The Academy of Management Review, Vol. 17 No. 4, pp. 701-728.

\section{About the author}

Tapio Jukka received his MSc in Economics and Business Administration at University of Jyväskylä, Finland, in 2013. He is currently a Doctoral Student at University of Jyväskylä, School of Business and Economics. His main interests are how top management affects performance and management control. Tapio Jukka can be contacted at: tapio.j.jukka@student.jyu.fi

For instructions on how to order reprints of this article, please visit our website: 